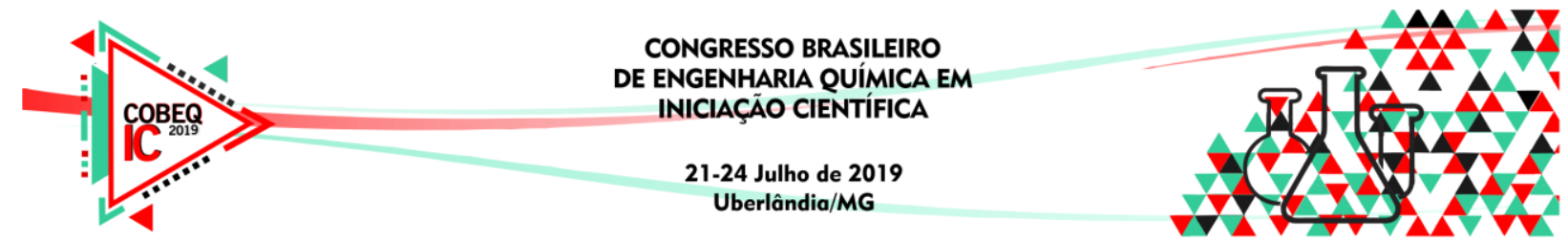

\title{
POTENCIAL ECONÔMICO DO CAFÉ NO SUL DE MINAS GERAIS
}

\author{
Bruna Mariane Ferreira
}

\author{
Universidade Federal de Alfenas, Faculdade de Bacharelado Interdisciplinar em \\ Ciência e Tecnologia. \\ E-mail para contato: brunaferreira.unifal@gmail.com
}

\begin{abstract}
RESUMO- O café, bebida presente em diversos países, é rico não somente em sabor, mas também em substâncias essenciais para a saúde e beleza do corpo humano. Este fruto é composto desde minerais como o Ferro e o Magnésio a vitaminas como a niacina (vitamina B3), essencial para a circulação sanguínea do corpo. A forma de consumo do grão faz com que se perca muitas substâncias e deixe de aproveita-las, resultando em um grande desperdício de lipídios, aminoácidos e polissacarídeos, substâncias as quais são de extrema importância para o desenvolvimento de produtos farmacêuticos e de cosméticos. Ao passar pelo o processo de torrefação, por exemplo, o café perde muitas propriedades, as quais serviriam de grande aplicação na indústria. Este projeto apresenta informações de um banco de dados, contendo estudos feitos na área da engenharia química sobre o fruto cafeeiro, suas aplicações e forma de extração de cada composto, com destaque na extração com $\mathrm{CO}_{2}$ (dióxido de carbono), que possui um valor acessível e é de fácil manipulação. O intuito destas informações é agregar valor ao café regional, com foco no sul de Minas Gerais, e futuramente nacional. A região do Sul de Minas Gerais é um dos principais exportadores de café no Brasil, no qual juntamente com a região Centro-Oeste do estado chegaram a produzir no ano de 2014, cerca de 17,7 milhões de sacas de café (Conab Companhia Nacional de Abastecimento -,2014). Dados como este mostram que é de extrema riqueza para a região demais formas de aplicações para o fruto.
\end{abstract}

\section{INTRODUÇÃO}

Dados publicados pelo CECAFÉ - Conselho dos Exportadores de Café do Brasil, o Brasil exportou 30,3 milhões de sacas no encerramento do Ano safra 2017/2018 -junho de 2017 a junho de 2018- (CECAFÉ,2018). As principais qualidades do grão a serem exportados foram a Arábica e Conillon. O fruto cafeeiro exportado, atualmente é somente usado para o consumo, sendo o principal delas a bebida. O presente projeto apresenta os compostos contidos no grão de café, suas formas de aplicações, preços e também formas de extrações para que haja uma possibilidade futura de que a UNIFAL (Universidade Federal de Alfenas), tenha em seus arquivos um banco de dados com o intuito de propor aos cafeicultores regionais formas de extrações das substâncias e aplicações para que desta forma possam agregar valor ao seu produto. A indústria farmacêutica brasileira tem um grande mercado interno, que chegou a movimentar em 2016 cerca de $\mathrm{R} \$ 85,35$ bilhões, segundo dados da INTERFARMA - Associação da Industria farmacêutica de pesquisa. Cerca de $\mathrm{R} \$ 48,59$ 


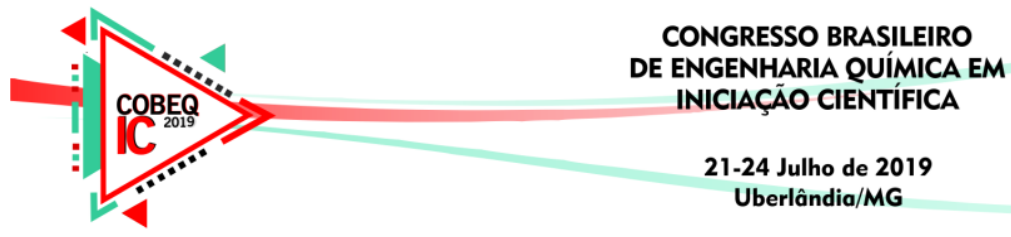

bilhões, faturados pelos dez primeiros grupos farmacêuticos, excedendo assim mais que 50\% do mercado varejista (INTERFARMA,2016). Esses dados são um exemplo de aplicação do fruto cafeeiro, o mesmo que é rico em minerais, vitaminas, lipídios e polissacarídeos, substâncias nas quais são muito utilizadas por indústrias farmacêuticas e de cosméticos.

\section{REVISÃO BIBLIOGRÁFICA}

\subsection{Importância econômica do café no Sul de Minas Gerais}

O estado de Minas Gerais, contendo mais de um milhão de hectares produz mais de $50 \%$ de toda safra brasileira de café. A principal renda de agricultores mineiros vem da venda do grão, o qual é vendido para mais de 60 países do mundo, e com uma alta taxa de exportação. A tabela 1 apresenta dados publicados pelo CECAFÉ (Conselho dos Exportadores de Café do Brasil), no qual mostra os dados de exportação e embarque do fruto, sendo apresentado o volume de regiões do Sul de Minas como Poços de Caldas, Varginha e Guaxupé, as quais estão entre as unidades com maiores índices de exportação do país (CECAFÉ,2018).É importante evidenciar que o embarque não ocorre na região Sul de Minas por não haver portos.

Dados publicados pelo Conab (Conab,2014), mostram que os cafeicultores da região de Minas Gerais produziram no ano de 2014, 22,6 milhões de sacas de café, sendo 17,7 milhões destas provenientes do Sul e Centro-Oeste do Estado.

Tabela 1- Unidades de Despacho x Unidades de Embarques - Período Janeiro a junho 2017

(CECAFE,2018)

\begin{tabular}{|c|c|c|c|c|}
\hline & \multicolumn{3}{|c|}{ JANEIRO a JUNHO 2017 (Sacas 60 kg) } \\
\hline Unidades Receita Federal & \multicolumn{2}{|c|}{ Despacho } & \multicolumn{2}{c|}{ Embarque } \\
\hline & Volume & Part.(\%) & Volume & Part.(\%) \\
\hline SANTOS & 10.703 .646 & 70,9 & 13.097 .991 & 86,7 \\
\hline RIO DE JANEIRO & 1.334 .615 & 8,8 & 1.369 .459 & 9,1 \\
\hline RIO DE JANEIRO & 1.195 .138 & 7,9 & 1.229 .542 & 8,1 \\
\hline SEPETIBA & 139.477 & 0,9 & 139.917 & 0,9 \\
\hline PARANAGUÁ & 229.693 & 1,5 & 231.003 & 1,5 \\
\hline VITORIA & 859.454 & 5,7 & 55.972 & 0,4 \\
\hline SALVADOR & 59.456 & 0,4 & 59.456 & 0,4 \\
\hline REDEX GUAXUPÉ/JAPY & 1.427 .967 & 9,5 & & 0 \\
\hline REDEX POÇOS DE CALDAS & 152.299 & 1 & & 0 \\
\hline EADI VARGINHA & 58.425 & 0,4 & & 0 \\
\hline RODOVIÁRIO & 277.049 & 1,8 & 288.929 & 1,9 \\
\hline OUTROS & 2.808 & 0 & 2.602 & 0 \\
\hline TOTAL & $\mathbf{1 5 . 1 0 5 . 4 1 2}$ & $\mathbf{1 0 0}$ & $\mathbf{1 5 . 1 0 5 . 4 1 2}$ & $\mathbf{1 0 0}$ \\
\hline \multicolumn{4}{|l}{} &
\end{tabular}


Tabela 2 - Sacas de café exportadas por região de Minas Gerais no ano de 2014

\begin{tabular}{|c|c|}
\hline Região de Minas Gerais & Quantidade de Sacas exportadas \\
\hline Sul / Centro-Oeste & 10,7 milhões \\
\hline Cerrado Mineiro & 5,8 milhões \\
\hline Zona da Mata & 5,3 milhões \\
\hline Norte de Minas & 762 mil \\
\hline
\end{tabular}

\section{METODOLOGIA}

Para a pesquisa, foi realizada uma coleta bibliográfica aplicada, a fim de adquirir conhecimentos, para que futuramente possa haver uma aplicação pratica do fruto cafeeiro em áreas distintas. É valido ressaltar a possibilidade de extração das propriedades do grão, visando manter o sabor para que posteriormente ele possa ser reutilizado em bebidas.

\section{RESULTADOS E DISCUÇÕES}

\subsection{Composição Química do Café}

Estudos publicados como Clarke e Macrae e Encyclopedia of Food Science, Tecnology and Nutrition Academic Press, apresentam a composição química dos grãos de café verdes.

Tabela 3- Composição Química dos grãos de café verdes ( \% base seca)(Clarke e Macrae, 1985).

\begin{tabular}{|c|c|c|c|c|}
\hline Componentes & \multicolumn{2}{|c|}{ Arábica } & \multicolumn{2}{c|}{ Robusta } \\
\hline Minerais & 3 & 4,2 & 4 & 4,5 \\
\hline Cafeína & 0,9 & 1,2 & 1,6 & 2,4 \\
\hline Trigonelina & 1 & 1,2 & 0,6 & 0,75 \\
\hline Lipídios & 12 & 18 & 9 & 13 \\
\hline Total de ácidos Clorogênicos & 5,5 & 8 & 7 & 10 \\
\hline Ácidos Alifáticos & 1,5 & 2 & 1,5 & 2 \\
\hline Olissacarídeos & 6 & 8 & 5 & 7 \\
\hline Total de Polissacarídios & 50 & 55 & 37 & 47 \\
\hline Aminoácidos & 2 & & 2 & \\
\hline Proteínas & 11 & 13 & 11 & 13 \\
\hline
\end{tabular}

A seguir será apresentado alguns dos compostos estudados, aplicações, preços e forma de extração para os mesmos.

\subsubsection{Minerais}

O café como apresentado na tabela 3 , é rico em minerais, e alguns desses são o ferro, o potássio, cálcio e sódio. Substâncias muito utilizadas no mercado de cosméticos e que possuem uma média de preço de $\mathrm{R} \$ 18.726,67$ a tonelada. 


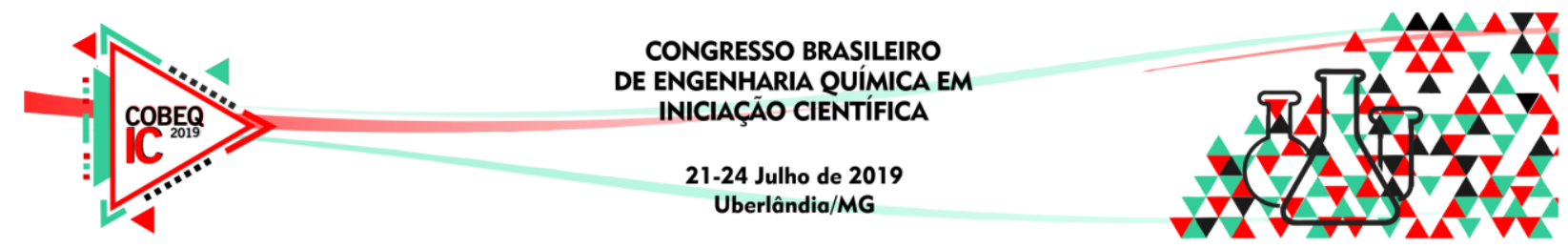

\subsubsection{Cafeína}

A cafeína é um dos alcaloides (componentes do grupo de compostos nitrogenados orgânicos derivados das plantas, possuem inúmeras propriedades farmacológicas, sendo assim, muito utilizados na fabricação de remédios), apresenta inúmeros benefícios fisiológicos no ser humano, estes que frequentemente estão relacionados ao consumo do café. Possui um preço médio de $\mathrm{R} \$ 4.670,00$ o kg (quilograma).

A forma de atuação da cafeína no corpo humano é similar às anfetaminas e à cocaína, possuindo efeitos mais fracos que as drogas citadas, apesar de agir nos mesmos receptores do SNC (sistema nervoso central). A ligação da adenosina, um neurotransmissor natural, aos seus receptores no cérebro, diminui a atividade neural, dilata os vasos sanguíneos, entre outros. A cafeína se liga aos receptores da adenosina e impede a ação da mesma sobre o SNC, estimulando a atividades neural causando a constrição dos vasos sanguíneos. (Azevedo Álvaro 2005).

$\mathrm{Na}$ medicina, por exemplo, a cafeína é utilizada como um estimulante cardíaco e diurético, além de ser utilizada também na produção de remédios para enxaqueca. Com a ingestão da cafeína é liberado no organismo uma grande quantidade de adrenalina, causando assim uma série de efeitos no corpo humano, como taquicardia, aumento da pressão arterial, abertura dos tubos respiratórios (motivo de muitos medicamentos para a asma possuírem cafeína, aumento do metabolismo e contração dos músculos.

Removendo a cafeína de produtos, podem-se obter produtos descafeinados, convenientes para o uso de consumidores intolerantes a cafeína e ao mesmo tempo fornecer alcaloide para indústrias farmacêuticas.

Para a extração de alcaloides em industrias, geralmente são utilizadas técnicas convencionais como a utilização de solventes químicos imiscíveis na água. Para a purificação de alcaloides dos extratos obtidos, técnicas como destilação, cristalização dentre outras são de extrema importância. Porém utilizar estes métodos são apresentadas desvantagens como a formação de resíduos indesejáveis (provenientes dos solventes químicos usados na extração e/ou de alterações no produto final pela degradação térmica devido às altas temperaturas alcançadas durante as etapas de extração e purificação). (Azevedo Álvaro 2005)

Um excelente solvente para a cafeína é a água, mas sua desvantagem é possuir uma baixa seletividade, resultando na extração de outros componentes das matrizes vegetais juntamente com a cafeína, trazendo assim a necessidade de outras etapas demoradas e dispendiosas no processo de purificação do alcaloide. Segundo Álvaro (2005), é possível realizar a extração da cafeína com a utilização do $\mathrm{CO}_{2}$ supercrítico, mas o mesmo não é tão eficaz na cafeína como é nos lipídios presentes no óleo de café.

\subsubsection{Lipídios}

Os lipídios, também chamados de gorduras, pertencentes ao café são encontrados em seu óleo vegetal, constituinte do endosperma do grão, e também nas ceras localizadas nas camadas exteriores dos grãos. São encontrados no óleo de café, o qual traz inúmeros benefícios a saúde, pode ser aplicado em remédios por ser um antidepressivo natural além de ajudar no controle da glicose no organismo. Possui propriedades de hidratação e atua como um rejuvenescedor.

A tese de doutorado de Álvaro Bandeira Antunes de Azevedo -Mestre em engenharia química - publicado em 2005, propõe a extração do óleo de café através de fluidos supercríticos, segundo ele. 


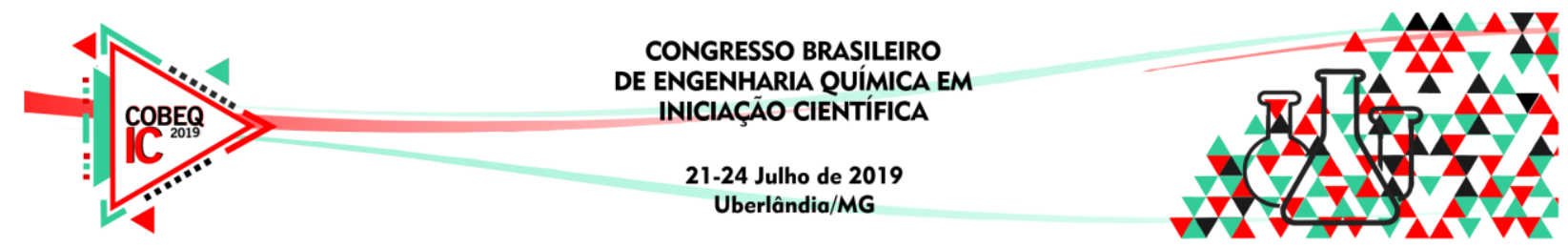

"Uma substância encontra-se no estado supercrítico quando está a uma temperatura acima da sua temperatura critica $(\mathrm{T} / \mathrm{Tc}>1)$ e uma pressão acima da sua pressão critica ( $\mathrm{P} / \mathrm{Pc}>1)$. Nessas condições, a substância adquire um comportamento intermediário entre gases e líquidos. A densidade (que confere ao fluido a capacidade de solubilizar outras substâncias) assume valores que podem ser comparados a densidades características de líquidos (a altas pressões). Sua pequena viscosidade, que é similar a dos gases, e a difusividade intermediária entre gases e líquidos permitem-lhe penetrar nos pequenos espaços e poros dos materiais sólidos dos quais se quer extrair o soluto (McHough e Krukonis; 1994). Estas propriedades aumentam a taxa de transferência de massa do soluto comparada à extração com solvente líquido no mesmo período de tempo. No ponto crítico, a compressibilidade isotérmica da substância tende ao infinito e, na proximidade do ponto crítico, pequenas mudanças na pressão causam grandes variações no volume molar e na densidade."

A utilização de tecnologias como a Extração com Fluidos Supercríticos (EFS), quando realizada com $\mathrm{CO}_{2}$ como solvente, é de extrema vantagem pois o mesmo possui um uso limpo, não inflamável, atóxico e não poluente. É importante ressaltar que o $\mathrm{CO}_{2}$ supercrítico, possui uma afinidade maior pelos lipídios presentes no óleo de café. Além de que o custo associado a está pratica se torna mais vantajoso ao se comparar com métodos tradicionais, os quais são realizados com líquidos necessitando posteriormente de uma outra forma de separação (Azevedo Álvaro 2005).

O óleo de café possui um preço médio de R \$1.120,00 o litro.

\section{CONSIDERAÇÕES FINAIS}

O estudo realizado possibilitou uma visão de extração de propriedades dos componentes químicos do café com o intuito de aplicação diversificada do produto. Para estudos futuros, é possível realizar uma coleta de dados que possibilite, apresentar propostas direcionadas a utilização do grão após a extração de seus componentes, visando seu redirecionamento para o processo de torrefação, com o intuito de que seja aproveitado de todas as formas os benefícios econômicos envolvidos na produção do café agregando assim mais valor ao café regional.

\section{Referências}

ABASTECIMENTO, Conab Compania Nacional de. Acompanhamento da safra brasileira café: safra 2014.

Disponível em: <file:///C:/Users/Bruna/Desktop/Boletim_Cafe_Maio_2014.pdf>. Acesso em: 16 out. 2018. ABIC, Associação Brasileira da Indústria de Café. A Expansão do café no Brasil. 2018. Disponível em: <http://abic.com.br/o-cafe/historia/a-expansao-do-cafe-no-brasil/>. Acesso em: 19 out. 2018.

AZEVEDO, Alvaro Bandeira Antunes de - Tese de doutorado -Extração e recuperação dos princípios ativos do café utilizando fluidos supercríticos. SP, UNIVERSIDADE FEDERAL DE CAMPINAS, 2005. 


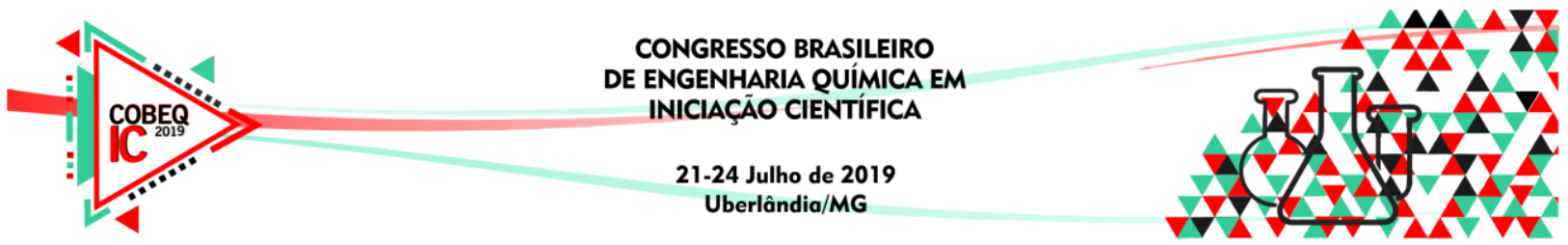

CAFÉ, Amiste. Conheça os diferentes tipos de café no Brasil. 2017. Disponível em: $<$ https://amiste.com.br/conheca-os-diferentes-tipos-de-cafe-no-brasil/>. Acesso em: 02 ago. 2018.

CECAFÉ. Relatório mensal de exportações. 2018. Disponível em: <https://www.cecafe.com.br/publicacoes/relatorio-de-exportacoes/>. Acesso em: 08 ago. 2018.

CLARKE, R.J., MACRAE, R., Coffee Chemistry. V 1, London, Mew York, Elsevier Applied Science Publishers, 1985.

COFFEE SCIENCE, Lavras, v. 2, n. 2, p. 97-111, jul./dez. 2007

INTERFARMA, Associação das Industrias Farmacêuticas de Pesquisas. Relatório de Sustentabilidade 2016 Ano Base 2015. Disponível em: <https://www.interfarma.org.br/public/files/biblioteca/guia-interfarma-2016interfarma1.pdf >. Acesso em: 19 out. 2018.

MAUL, A. A ., Fluidos Supercriticos- Situação Atual e Futuro da extração Supercrítica, Biotecnologia Ciência \& Desenvolvimento, Ano II, No.11. Pp. 42-46,1999

NIKOLOVA- Damyanova, B., VELIKOVA, R. E., JHAM, G.N., Lipid classes fatty acid composition and triacyglycerol molecular species in crude coffe beans harvested in Brasil. Food Research International, V.3(6), pp 479-486,1998.

OLIVEIRA, G. S. Comparação química dos grãos de café (Coffea arabica), sadio e seus grãos PVA (pretos, verdes, ardidos) oriundos do Sul de Minas e do Cerrado Mineiro, submetidos a diferentes graus de torrefação. 2006. 113 f. Dissertação (Mestrado em química orgânica) - Universidade Federal de Uberlândia, Uberlândia, 2004. 